\title{
Parecer sobre o projecto de Co- digo Criminal dos Estados Unidos do Brasil (*)
}

Raphael Sampaio Noé Azevedo

A leitura attenta desse Projecto nos deixou a impressão de que o progresso, porventura contido nas suas innovações, não compensará a grande perturbação que teremos de presenciar no funccionamento da nossa justiça criminal.

Os grandes institutos de Direito Penàl, tradicionalmente applicados em nosso Paiz, são profundamente golpeados pelos novos preceitos.

Haverá grande dispersão de idéas na doutrina e na jurisprudencia quanto ao entendimento de innumeros artigos desse Codigo.

Os conceitos não são claros nem precisos. Afastam-se dos ensinamentos classicos e não traduzem bem as novas tendencias penaes.

Tendo fallecido o notavel civilista, autor do Projecto, que poderia commentar o futuro codigo, mais difficil ainda ha de ser a interpretação das suas disposições.

Rendemos, todavia, as nossas homenagens de sincera admiração por esssa obra, sulcada por um espirito creador e que poderia servir de base para uma grande refórma penal, mas em ambiente diverso do nosso.

(*) Approvado pela Congregação da Faculdade de Direito, em 4 de setembro de 1937. 
Uma vez, porém, que esse Projecto foi adoptado pelo Congresso para servir de base á reforma do Direito Criminal Brasileiro, apresentamos aqui as nossas observações sobre os pontos capitaes.

\section{FALTA DE DISPOSITIVO SOBRE A INTERPRETAÇÃO DA LEI PENAL}

Emquanto a pena constituir um mal para aquelle a quem se inflige, as leis penaes hão de estar sujeitas áquella regra do direito classico, que se traduz no brocardo: benigniora amplianda odiosa restringenda.

A suppressão da regra que figurava nos codigos anteriores póde dar a entender que nos deixamos influenciar pelo direito penal das dictaduras da Russia ou da Alemanha, permittindo a ampliação ou a applicação analogica do dispositivo penal mesmo contra o réu.

Demais, temos o preceito generico do art. 113, n. ${ }^{\circ} 37$, da Constituição Federal, dispondo:

"Nenhum juiz deixará de sentenciar por motivo de omissão na lei. Em tal caso, deverá decidir por analogia, pelos principios geraes de direito, ou por equidade".

o silencio do Codigo Penal, alliado a essa disposição constitucional, póde levar á conclusão de que a interpretação analogica não é vedada nesse ramo do direito, mesmo. em prejuizo dos accusados.

Continuando as penas previstas no Projecto com o caracter de mal ou soffrimento para o delinquente, a regra nullum crimen sine lege não constituirá garantia sufficiente, sem o complemento do preceito prohibitivo de interpretação analogica ou extensiva para a applicação da pena. 


\section{DA TENTTATIVA}

Embora sejam subjectivistas as nossas tendencias, achamos arrojada a equiparação da tentativa ao crime consumado, para o effeito da pena, sempre que se trate de reincidente ou criminoso por indole.

Alargado, como foi, o conceito da reincidencia, ella nem sempre será indicio vehemente de periculosidade, por outro lado, a indole criminosa manifestada por uma tentativa que não chegou a produzir damno, reclamaria de preferencia á penalidade do crime consumado, a applicação de uma medida de segurança.

Segundo o art. 42, n. ${ }^{\circ}$ II do Projecto, "a indole criminosa se revela pela perversidade da concepção ou pela atrocidade da execução". Sendo apenas iniciada a execução, na tentativa, torna-se difficil ajuizar da sua atrocidade.

Assim, a pena do crime consumado virá recahir exclusivamente sobre a perversidade da concepção. Será a punição applicada quasi que exclusivamente ao elemento interno.

Parece, portanto, que ha exaggero de subjectivismo.

\section{LEGITIMA DEFESA}

A expressão - "usando dos meios que as circumstancias permittem" - empregada pelo art. 10, tira o rigor de acção imposta pela necessidade, que constitue a substancia. da legitima defesa.

$O$ requisito da proporcionalidade não figura no corpo da definição. 0 criterio estabelecido pelo $\$ 22^{\circ}$, para se afferir a legitimidade da defesa, não contém uma exigencia de proporcionalidade.

Não exigimos a proporcionalidade mathematica. Achamos, porém, que o criterio desse paragrapho vem afrouxar 
muito o conceito dessa justificativa, tão rigorosamente estabelecido pelo nosso direito actual.

Por outro lado, risca-se a presumpção de legitima defesa do art. 35, $\S 1 .{ }^{\circ}$, do Codigo vigente, que muito concorre para a segurança das habitações, atemorizando os assaltantes.

$\mathrm{E}$ ainda é de se notar que sendo a honra legitimamente defendida pela retorsão prevista no art. 214, a sua inclusão no art. 10 levará os uxoricidas a pleitearem essa defesa. E ahi não sabemos como armar a proporção entre a aggressão e a defesa...

\section{DA IMPUTABILIDADE}

Dará logar a grande celeuma a admissão do conceito de imputabilidade restricta que se vê no art. 19, parte final.

Certos estados da mente poderão determinar a attenuação da pena que deva soffrer o individuo imputavel. Attenua-se a penalidade. Mas o conceito de imputabilidade não se alarga, nem se restringe. Ou o deliquente é imputavel e póde ser punido mais ou menos intensamente, conforme o seu estado mental; ou é inimputavel e a nenhuma pena estará sujeito.

\section{DEFINIÇÃOO DO DOLO}

A expressão - "quando se devessem prevêr, como necessarias ou provaveis as consequencias, etc." - focaliza hypotheses de previsibilidade e não de previsão (art. 26).

Parece-nos melhor a doutrina que liga o dolo á previsão, classificando como de culpa os casos de previsibilidade.

\section{SUPPRESSÃO DA CUMPLICIDADE}

A participação accessoria ou accidental no crime não deve ser equiparada á autoria. Essa novidade do Codigo italiano não deve seduzir o legislador brasileiro. 
Mesmo seguindo-se uma orientação subjectivista, chegase á conclusão de que a cumplicidade deve ser punida mais brandamente, pois a participação accessoria revela menos periculosidade do que a acção directa ou principal.

\section{REPARAÇÃO DO DAMNO}

Opinamos pela manutenção do systema actual de independencia das responsabilidades civil e criminal, consagrado pelo art. 1525 do Codigo Civil, que deixou perfeitamente esclarecidas as duvidas que antes se levantavam em face das disposições do art. 68 da lei de 1841 e 31 do Codigo Penal. Não vemos sequer necessidade da excepção estabelecida pelo art. 276 do Codigo Penal vigente.

Devemos arredar o mais possivel o interesse economico das acções criminaes, para que a justiça repressiva realize a sua finalidade precipua que é a da defesa social e manutenção da ordem e segurança publica, sem se influenciar pelo odio das familias das victimas ou pelo desejo de locupletamento a pretexto de justa reparação.

$O$ interesse privado, ligado ás acções criminaes, perturbará sempre a distribuição da Justiça. Se não conseguimos attingir o ideal da reparação pelo proprio Estado de todo o damno resultante dos delictos, segundo o alvitre de Ferri e as aspirações de Garofalo, Bentham e Gioia, ficando com uma acção regressiva absolutamente impessoal contra os delinquentes, é melhor mantermos o systema de separação dos interesses economicos dos particulares ou victimas dos delictos, do interesse social de manutenção de ordem e segurança geral, que se realiza por meio da acção criminal.

Além disso, não nos parecem prudentes as profundas innovações que se introduzem no Direito Civil e no Direito Commercial, por força das disposições dos arts. 32 a 39 do Projecto. 
Hoje, quem causa damno a terceiro, para evitar mal maior, é obrigado a reparal-o.

Pelo preceito do art. 32 do Projecto, com remissão ao art. 8. ${ }^{\circ}$, essa obrigação ficará excluida. Tambem num caso de "aberratio ictus", na legitima defesa, em que um terceiro seja sacrificado, se excluirá a possibilidade de indemnização actualmente admittida pelos nossos tribunaes.

Esses terceiros sacrificados, pelos actos necessarios para a salvação dos ameaçados ou aggredidos que reagem legitimamente, pódem deixar as familias na miseria se os aggressores não estiverem em condições de fazerem a reparação.

Parece mais justo obrigar-se o que se beneficiou com a defesa a compensar esses prejuizos causados a terceiros, ainda que sem culpa, do que deixar essas victimas que nada tinham a vêr com o caso, ou suas familias, sem reparação alguma.

A determinação do $\S 20^{\circ}$ do art. 32 , sobre a solidariedade dos socios de uma sociedade commercial, quanto á reparação do damno causado por um delles, revoga os preceitos do Codigo Commercial e das leis sobre sociedades commerciaes, isentando os socios commanditarios, os socios das sociedades por quotas, e as accionistas das sociedades anonymas, que tambem são socios, de toda e qualquer responsabilidade, pelos actos praticados pelos gerentes ou administradores.

\section{ABUSO DA PRISÃO DE CURTA DURAÇÃO, SOB O NOME DE DETENÇÂO}

A prisão de cutrta duração em commum é combatida por todos os penitenciaristas. E' sufficiente para corromper e insufficiente para regenerar. Corrompe os delinquentes primarios, postos em contacto com os profissionaes do crime. E não corrige os que precisam de emenda, por ser curta e desacompanhada de trabalho educativo. 
O que o Projecto institue sob o nome de "detenção" vem a redundar numa prisão de curta duração em commum. Pelo que dispõe o art. 63 , n. ${ }^{\circ}$ III, é obrigatorio somente o isolamento nocturno.

Se essa prisão tem de ser cumprida num estabelecimento especial, com cellulas para isolamento nocturno, seria preferivel estabelecer como regra tambem o isolamento diurno, para evitar a acção dos máus sobre os bons.

Como o Projecto prodigaliza a detenção por curto prazo, prescrevendo-a a todo passo, ora por dias, e ora por mezes, seria preferivel a regra do isolamento.

Quando fôsse prescripta por alguns mezes, ou annos, então estabelecer-se-ia um regimen de trabalho, de exercicios e mesmo de diversões em commum, mas por grupos previamente estudados e seleccionados, para evitar a influencia perniciosa dos peores ainda que primarios sobre os melhores.

\section{MEDIDA DA PENA}

O relator deste parecer tem sempre defendido a doutrina da individualização da pena. Não teme o arbitrio do juiz. Mas preconiza a transformação da pena em tratamento. Este será sempre um bem para o paciente. Devendo o juiz sempre beneficiar e não castigar o delinquente, se não desapparecerem de todo os perigos de arbitrariedade serão certamente muito diminuidos.

Mas, continuando a pena no Projecto a ser pena, com todos os caracteristicos de mal infligido ao delinquente por causa do mal por elle commettido, temos de ser mais cautelosos nos ensaios de individualização.

A livre attenuação e aggravação até os minimos e maximos genericos ou especificos, que ora se admitte expressamente no Projecto, e ora se facilita ao juiz a quem se deixa a apreciação das circumstancias aggravantes e attenu- 
antes, afigura-se-nos constituir um systema muito avançado no caminho da individualização.

Por outro lado, temos as novas figuras de aggravantes e attenuantes ideadas pelo Projecto. Ellas não offerecem uma conceituação precisa. No seu reconhecimento terão os juizes ụm largo campo para o arbitrio. Não terão a pealos nem o rigor dos textos que são frouxos, nem a licção da doutrina, nem a estratificação da jurisprudencia.

Assim, "a pena será diminuida quando... crise moral profunda ou sem culpa sua (do criminoso), situação angustiosa o empolgava", (art. 101, n. ${ }^{\circ}$ III).

Até que se defina pela pratica judiciaria o que vem a ser "crise moral profunda" e "situação angustiosa", haverá muito panno para envolver o romantismo de muitos juizes.

E como essa figura existem outras.

Desprezaram-se quasi que inteiramente as aggravantes. e attenuantes do antigo Codigo e dos codigos classicos, figuras que vinham se definindo através do tempo por um paciente trabalho dos penalistas e dos tribunaes.

Não podemos, por isso, louvar semelhante desprezo a tanto saber e ponderação.

Dir-se-á que o systema classico é demasiado rigido, sendo quasi mecanico o trabalho do juiz na fixaçầo da pena. Seria caso para abrandal-o, mas não para uma reforma tão radical, como a que apparece no Projecto.

\section{DA EXTINCÇÃO DA CONDEMNAÇÃO}

Enumerando as causas extinctivas, o art. 136 distingueo indulto do perdão.

Mas, no art. 137, usa do termo perdão, querendo evidentemente se referir ao indulto.

Não approvamos tambem a disposição que extende aos coautores o beneficio do "perdão" ou indulto concedido a um delles. 
Provindo o indulto de um acto de soberania e podendo ser concedido em attenção a meritos excepcionaes de um dos co-autores, não vemos razão para a participação obrigatoria dos demais nesse beneficio.

\section{PARTE ESPECIAL}

Estranhamos que o Projecto tenha dividido a parte geral em dois titulos e tenha deixado a parte especial, muito mais extensa, subordinada á divisão sómente de capitulos.

E' tradicional nos codigos classicos a divisão da parte especial em titulos, dando-se a cada um delles a epigraphe indicativa do bem juridico offendido.

Assim, pela epigraphe de cada titulo determina-se a natureza dos crimes ahi capitulados. A sciencia não é mais do que uma classificação de conhecimentos. Se na sciencia penal tem-se adoptado o systema de classificar as differentes figuras delictuosas em capitulos, subordinados a titulos onde se enfeixam os crimes da mesma natureza, parece que não havia mal em manter-se tal systema.

\section{DO HOMICIDIO}

Tendo sido tão pobre a enumeração de aggravantes na parte geral, esperavamos ao pé de cada crime encontrar uma relação de circumstancias aggravantes especiaes.

De facto, em seguida á definição do crime de homicidio deparamos com oito aggravantes especiaes. Mas, faltam algumas importantissimas. Esqueceu-se, por exemplo, das aggravantes de premeditação e do caso de veneficio. Seria muito mais importante tratar do homicidio commettido por meio de veneno, do que mediante o uso do automovel, aviões, barcos motores, etc.

Seria muito mais comprehensiva a aggravante do $\S 18$ do art. 39 do Codigo actual, do que a do n. ${ }^{\circ}$ IV do art. 165 do Projecto. 
Qualquer individuo que se aproveite da afflicção dos seus semelhantes, provocada por incendios, innundações, calamidades e outras desgraças, para commetter crimes, revela grande perversidade, pouco importando que essa anormalidade da situação provenha de uma fatalidade natural, ou de uma acção criminosa do proprio delinquente ou de outrem.

\section{DO INFANTICIDIO}

O novo Codigo italiano corrigiu uma falha do antigo, prevendo a hypothese do feticidio, isto é, da morte da criança durante o trabalho do parto natural.

Tal hypothese não podia se enquadrar nem no abôrto, nem no infanticidio.

0 art. 168 do Projecto pretendeu supprir essa falha que tambem se nota em nosso Codigo. Mas, somente pune a mãe que durante o parto mate o féto.

Tratando no artigo seguinte do infanticidio commettido pelos parentes, deixa de incluir a morte da criança durante o trabalho de parto.

Ora, quem está menos em condições de commetter o crime durante o parto é a mãe.

A parteira ou os parentes é que, ao assisteirem á parturiente, facilmente poderão supprimir a vida do féto.

\section{DUELLO}

O Projecto não define o duello, nem estabelece as condições que devem ser satisfeitas para a extraordinaria diminuição das penalidades, que prevê nos casos de ferimentos ou mesmo de morte.

Dessa fórma, qualquer combate singular e até mes. mo o chamado duello “á americana”, servirá de pretexto para desclassificação dos crimes de sangue, praticados por valentões que desafiem ou constranjam os seus desaffectos a se utilizarem das armas. 


\section{LESÕES CORPORAES}

0 uso do verbo lesar no sentido de ferir parece obsoleto. Além disso, exclue as hypotheses de offensa physica sem ferimentos, mas productores de dôr.

Não nos parece razoavel que somente a lesão determinadora de incapacidade permanente de trabalho, e não a determinadora de incapacidade temporaria, de longa duração, dêva qualificar o crime.

Se não acharem bom o criterio dos 30 dias, que estabeleçam outro. Mas não se póde considerar como leve uma lesão que deixe o paciente impossibilitado de trabalhar durante mezes ou annos.

A expressão do art. 183, n. ${ }^{\circ}$ II — "lhe mutilar o corpo, um dos membros ou orgams importantes etc." precisa ser corrigida. Mutilar é privar de algum membro. Do modo por que está redigido o texto, poder-se-á suppôr que constitue mutilação, por exemplo, o córte de um náco de carne nas nadegas ou noutro ponto do corpo onde haja abundancia de tecidos.

Em todo o caso póde ter sido essa a intenção dos autores do Projecto, impressionados com aquelle caso de Voltaire, de uma criatura linda, sujeita a essa profanação por um bando de beduinos. .

\section{DO FURTO QUALIFICADO}

O Projecto preferiu usar da expressão "furto qualificado" em vez de "roubo". Não o criticamos, por isso, embora nos pareça mais suggestivo e incomparavelmente mais forte a repulsa que se liga a essa palavra, do que aquella que se ligará á expressão complexa "furto qualificado".

Mas, onde encontramos a maior falha no Projecto é em sómente qualificar o "furto" quando haja violencia contra alguma pessôa. Esqueceu-se da violencia contra as cousas. 
Desse modo, serão condemnados por furto simples os arrombadores de casas e cofres, esse perigosissimos technicos, munidos de tão poderosos apparelhos, que atacam pela frente as burras as mais fortes, rompendo o melhor aço em ostentosas manif estações de força.

Notamos tambem o silencio sobre a escalada.

\section{DA CALUMNIA}

Não conseguimos conciliar as idéas dos arts. 206 e 207 no Projecto. O primeiro admitte que se prove a verdade da imputação tida como calumniosa, por via de excepção, exigindo que a prova seja contradictoria estabelecendo mais outras condições.

O segundo declara que só se admittirá como prova da verdade da imputação a cousa julgada. Se não houver cousa julgada paralyzar-se-á o processo pelo crime de calumnia até que se obtenha sentença com transito em julgado no outro feito.

Nessas condições, que é que se poderá provar contradictoriamente na excepção de verdade? Dirão que poderão ser provados factos que não dêm lugar á acção do Ministerio Publico, mas que exponham o offendido á desconsideração social.

Realmente, o art. 205, definindo a calumnia, considera tal não só a imputação de facto, que exponha o offendido á acção do Ministerio Publico, como tambem a de facto que o exponha á desconsideração social.

Mais isto é, evidentemente, injuria, incluindo-se na fórmula do art. 210 , onde se define este outro crime.

Desse modo, quanto á calumnia propriamente dita, a prova de verdade da imputação ficou reduzida ao caso julgado, no juizo competente.

Se não existir o caso julgado e o calumniador não puder promover o andamento do processo, para obter sentença final, ficará impossibilitado de defender-se. 
Essa restricção é excessiva, podendo-se mesmo dizer que fica inteiramente abolida a "exceptio veritatis" nos processos que sejam realmente de calumnia. Isso importará na abolição do direito de critica e de informação que cabe a todos os cidadãos honestos e escrupulosos, contra os desrespeitadores da lei.

\section{DO RAPTO}

$\mathrm{O}$ art. 227 sómente prevê o rapto, por meio de violencia, ameaça ou artificios. Não cogita do rapto consensual que é um crime commettido contra a segurança das familias.

$\mathrm{Na}$ systematica do Projecto as práticas sexuaes com o consentimento de mulheres maiores de 16 annos não constituem crime, só se incriminando os actos violentos ou fraudulentos.

Ha quem defenda e quem condemne esse criterio. Mas, quanto ás menores de 16 annos, o seu consentimento jamais poderá legitimar o acto do offensor.

Sendo absolutamente incapazes de consentir, a sua acquiescencia é inexistente em face do Direito. Em taes hypotheses a presumpção de violencia do art. 272 do actual Codigo Penal tem de ser mantida.

E, mantendo-se, convirá solucionar tambem a duvida que hoje existe de ser presumpção absoluta ou relativa. Sendo esta uma questão opinativa, o Congresso resolvendo por maioria interpretará o sentimento dominante.

\section{RAPTO PARA RESGATE}

Se não fôsse o reduzido numero de millionarios que ha no Paiz, e se os "kidnappers" americanos soubessem que aqui não ha cadeira-electrica e que a pena estabelecida para o rapto de menores com o fito de obter resgate - é de cinco annos apenas, com certeza haviam de transferir para aqui a séde de sua industria. 


\section{ESTUPRO DE MENOR DE 16 ANNOS}

$\mathrm{O}$ art. 255 pune "aquelle que constranger menor de 16 annos á conjuncção carnal".

Constranger, segundo Aulette, e na accepção visada pelo Projeto significa forçar, coagir.

Ora, quanto a menores de 16 annos a violencia deve ser presumida. Logo, não se deve falar em constranger, pois, para que o crime se consumme basta a conjunç̧ão carnal mesmo sem violencia.

\section{CRIMES CONTRA A NAÇÃO E CONTRA A PAZ INTERNACIONAL}

Foram fixados minimos de prisão muito baixos para a gravidade dos crimes ahi previstos. Não foram enumeradas aggravantes especiaes.

Das enumeradas no art. 104 sómente duas poderiam se applicar a taes crimes, mas essas mesmas serão consideradas como elementares.

Assim, é punido com cinco annos de prisão, no minimo, quem tentar submetter a Nação ou parte do seu territorio ao dominio estrangeiro.

Qual das aggravantes genericas poderiamos applicar ao caso? Parece-nos que somente as do art. 104, ns. I e IV serem vís os moveis do crime ou ter havido premeditada surpresa, engano, simulação ou fraude.

Mas não póde haver movel nobre em acção tão repugnante. E será impossivel uma tentativa dessa natureza, sem surpresa, engano, simulação ou fraude.

As penalidades dos arts. 408 e 409 são verdadeiramente ridiculas em face da gravidade dos factos que prevêm.

Comparem-se as penalidades desses capitulos com as de factos identicos, ou semelhantes, previstos nos arts. 241 e segs. do Codigo Italiano. Aquelle facto que nós punimos 
praticamente com cinco annos de prisão, é punido com a morte; e factos da mesma gravidade desses dos arts. 408 e 409, que o Projecto pune com detenção até 6 mezes e multa, o Codigo Italiano reprime com a reclusão de 5 a 12 annos.

Não é pelo facto de termos muita terra neste immenso Brasil, que havemos de tratar com mais benevolencia os que tentarem contra a integridade desse prodigioso legado dos nossos antepassados. E tambem não devemos confiar tanto na segurança das relações internacionaes do nosso Paiz, que descuidemos de reagir com energia contra os que tentarem perturbal-a.

\section{DAS CONTRAVENÇõES}

Dispõe o art. 416 que "não é licito aos Estados reprimir as contravenções locaes com penas diversas daquellas com que, neste Codigo, são reprimidas as geraes, nem adoptar criterio differente para a fixação da multa (art, 53), nem impôr pena privativa da liberdade por mais de tres mezes".

Não ficamos sabendo, entretanto, o que vêm a ser contravenções geraes.

Em seguida a esse artigo está a epigraphe - "Das contravenções em especie." Sob semelhante designação estão enumeradas todas as contravenções previstas no Projecto.

Logo, todas ellas são contravenções em especie, ou especiaes, e não contravenções geraes.

Se contravenções geraes são essas mesmas contravenções em especie, definidas pelo Codigo da União, para todo o Paiz, e se os Estados não pódem crear, outras, pois que não pódem punil-as com penas diversas, chega-se á conclusão de que os Municipios tambem não poderão punir as contravenções ás suas posturas.

Ficarão, assim, tanto os Estados como os Municipios muito cerceados nas suas attribuições de regulamentar diversos ramos da actividade publica. 
Bastará notar a impossibilidade de um regulamento do transito de vehiculos.

O Projecto somente prevê como contravenção na conducção de vehiculos a falta de habilitação e de exhibição da carta quando exigida. Se outras o Estado não puder crear, pois que outras penas não póde estabelecer, como se ha de reprimir o excesso de velocidade, a falta de observancia das direcções, a desobediencia aos signaes, o facto de não businar nas esquinas e tantas outras?

Dir-se-á que a regulamentação do transito vem a ser uma medida de policia. Mas, o art. 472 considera contraventor somente "aquelle que não observar as prescripções regulamentares sobre a ordem publica, a segurança geral e a hygiene, ou recalcitrar contra as medidas e ordens legitimas da autoridade a quem incumba por ellas velar".

A viação urbana não é um capitulo da ordem publica, nem da segurança geral, nem da hygiene.

Mas não é só por isso que entendemos desacertada a disposição do art. 416, pretendendo estabelecer paradigma para o poder de regulamentação dos Estados, e esquecendo-se de poder semelhante dos municipios. $\mathrm{O}$ seu maior desacêrto está em mandar observar nas multas o criterio do art. 53.

Se um pobre "chauffeur" desobedecer ao signal, a autoridade terá de indagar qual é a sua renda mensal, para achar o valor do dia-multa. Se fôr um grande capitalista terá de verificar qual a sua renda annual, consultando a Recebedoria de Rendas, para chegar ao "quantum" daquelle mesmo dia-multa, que será, incontestavelmente, muito maior do que o do "chauffeur" de praça.

Semelhante absurdo impossibilitará o policiamento do transito e de muitas outras actividades que os Estados e os Municipios têm o dever de regulamentar, e cujas prescripções têm de ser sanccionadas com multas fixadas de accôrdo com a gravidade da infracção. 


\section{TRAJOS INADEQUADOS}

Encontramos essa epigraphe encimando o art. 432. E vamos encontral-a novamente, embora travestida, acima do art. 481. A variação de "trajos inadequados" para "trajes indevidos" não mudou a materia tratada nesses artigos bem distanciados. Mas, apesar da repetição, ainda as disposições não ficaram completas. Em nenhuma dellas poder-se-á enquadrar o facto do leigo usar batina ou hábito.

Dir-se-á que o infractor estaria simulando profissão de padre ou de frade. Mas o padre não exerce profissão e sim um ministerio, e o frade faz profissão de fé mas não a exerce.

\section{EXPLORAÇÃO DE MENORES}

Tendo sido resalvada a vigencia do Codigo de Menores, o assumpto de que trata o art. 471 deve ficar disciplinado pelas disposições do mesmo, onde, aliás, vem tratado com bem maior amplitude.

\section{AFFIXAÇÃO DE CARTAZES}

$\mathrm{O}$ art. 479 pune com multa "aquelle que em logares publicos, nas paredes e muros das casas, affixar cartazes, estampas, desenhos, manuscriptos, ou escrever disticos ou letreiros sem licença da autoridade ou do dono".

Esqueceu-se das portas, janellas e portões.

$\mathrm{E}$ os estudantes de S. Paulo tambem diriam que o pedestal roliço, assim como a figura da estatua de José Bonifacio, escapariam á previsão desse texto. Não deixariam tambem de censurar o legislador por se deslembrar da historia de Pasquino. 
E nós lembramos que os moléques, que costumam fazer semelhantes diabruras, geralmente não têm dinheiro para pagar multa. A punição adequada seria uns dias de detenção.

São essas algumas das observações que nos occorrem sobre o Projecto em estudo, ora sérias, e ora leves, para despertar a reflexão, sem fadiga.

Ellas, entrtanto, nos dão a convicção de que seria melhor formular um novo Projecto. Para reformal-o nas questões de fundo, como é preciso, quebrar-se-á inteiramente o systema.

Por outro lado, a fórma em que elle está redigido afasta-se do estylo dos bons codigos. Pecca quanto á technica da linguagem. A falta de methodo na distribuição das matérias é evidente. O italianismo do "aquelle que", no começo de quasi todos os artigos, é irritante. A definição de um crime que se inicia no corpo do artigo, ás vezes só se conclue ao cabo de uma longa enumeração de modalidades, distribuidas por alineas e paragraphos.

São raras as disposições cujo alcance póde ser aprehendido pela primeira leitura. E nenhuma póde ser lida rapidamente. Não chegamos ao ponto de preconizar um codigo escripto em linguagem popular. Mas, é indispensavel que não haja mysterio nas fórmulas legaes. A criminalidade dos factos depende da definição legal. Se a ninguem é licito ignorar a lei, devemos facilitar a todos o seu conhecimento, formulando dispositivos tão claros quanto possivel.

São Paulo, 30 de agosto de 1937. 